\title{
FLIES: NUISANCE OR NECESSITY?
}

DIANA B. ROBSON, The Manitoba Museum, 190 Rupert Avenue, Winnipeg MB R3B ON2

\section{Introduction}

Few people would disagree that flies are a nuisance. While houseflies and fruit flies are usually just annoying, the biting flies, namely horse, deer and black flies, can inflict painful, itchy bites. Naturalists are less disdainful of flies than other people because they know flies are food for bats, birds and dragonflies. But flies are more than just fodder for hungry animals, they also pollinate plants. ${ }^{5}$

Flies are in the order Diptera along with mosquitoes and gnats. The word 'diptera' means "two wings" in Latin. The forewings of flies are large and

membranous while the hindwings are reduced to tiny bumps called halteres. The reduction of the hindwings gives the flies more maneuverability. ${ }^{1}$ Tiny claws and sticky pads on the legs of flies enable them to grip any surface, even while they are upside down. ${ }^{1}$ Their mouthparts are adapted for sucking or lapping up liquids, such as flower nectar.

To determine the potential importance of flies in the pollination of native plants, two study sites were sampled for flower visitor diversity during the summer of 2004: the Living

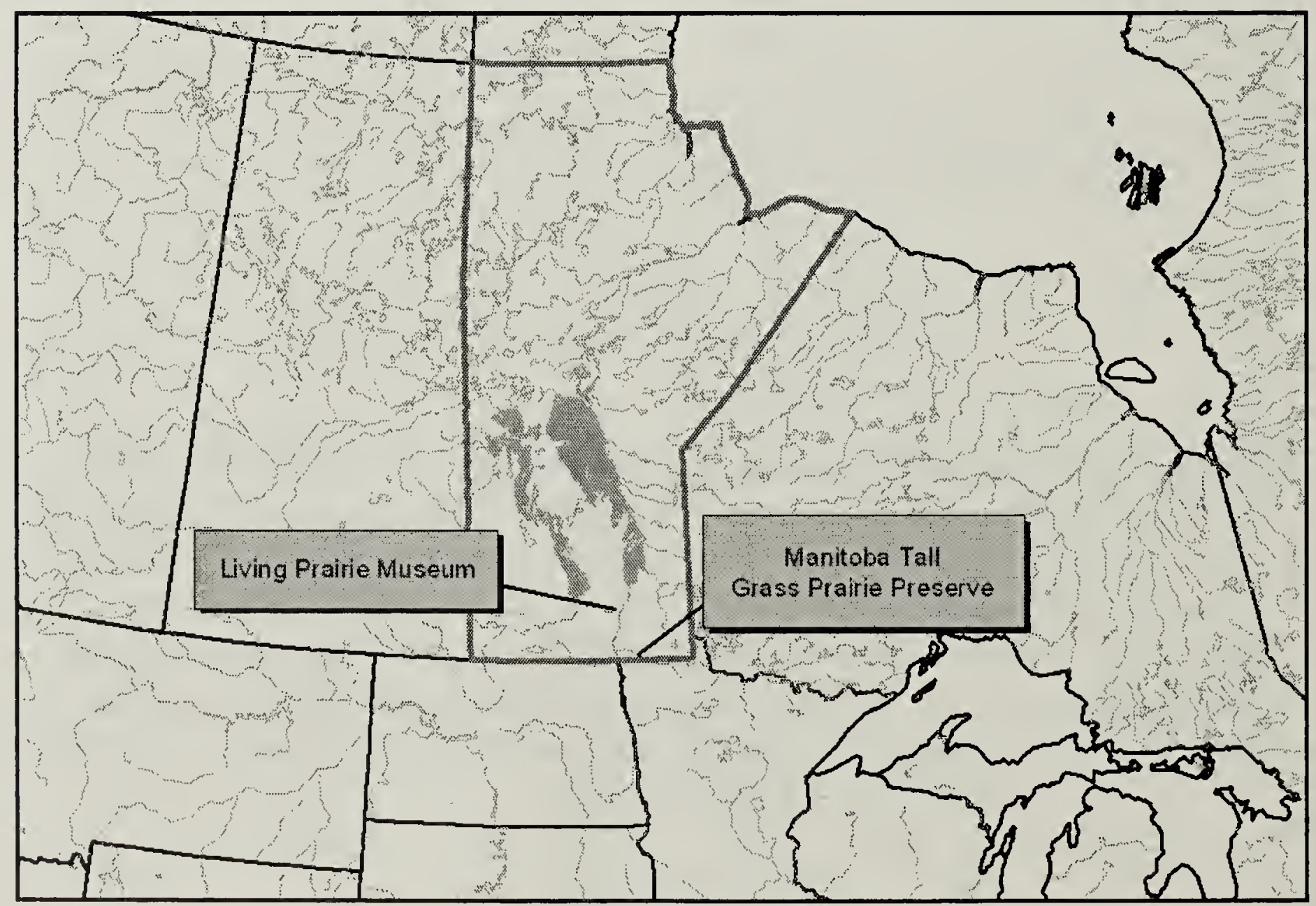

Figure 1. Location of study sites in Manitoba 
Prairie Museum (LPM) in Winnipeg, MB and the Tall Grass Prairie Preserve (TGPP) near Vita, MB (Fig. 1). The LPM is a 12-ha remnant of tallgrass prairie, completely surrounded by urban development. The TGPP is a considerably larger (2000-ha), more contiguous preserve. Both sites are in the Lake Manitoba Plain ecoregion and have a similar climate, although drainage is poorer at the TGPP.

\section{Methodology}

At each site, six $5 \mathrm{~m} \times 5 \mathrm{~m}$ plots were established. Sampling was done every two weeks, from the second week of June to the third week of September. The number of flowers each adult insect species visited in each plot was recorded. Each plot was surveyed for 60 minutes every sampling week. Since foraging activity is low in the early morning and late afternoon, surveys were typically conducted between 12 $\mathrm{pm}$ and $5 \mathrm{pm}$. The visitation sequence was randomized to correct for differences in insect visits during the course of the day. Regardless of whether insects were foraging for pollen or nectar, all were considered potential pollinators. At least one specimen of each insect species was captured, placed in a killing jar with ethyl acetate and frozen for later identification by Heather White (J.B. Wallis Museum, University of Manitoba). Voucher specimens for each plant species visited by an insect were collected from outside the sample plots. The plant and insect specimens were digitally photographed, and the images and specimens deposited in The Manitoba Museum.

\section{Results}

At least 60 species of insects representing four orders were observed feeding on nectar from (and possibly pollinating) 39 plant species (Table 1).
Just over half of the insect species observed were in the order Diptera. Dipterans were responsible for $64 \%$ of all floral visits (Fig. 2). The most important dipteran family was the Syrphidae (hover flies) (Fig. 3). Syrphids were responsible for $72 \%$ of all dipteran flower visits. One species in particular, Toxomerus marginatus, was observed feeding on the nectar of 22 different plant species throughout the summer. However, the efficacy of $T$. marginatus in pollinating those species may be low due to its small body size and lack of abundant hairs where pollen can attach. The Scatopsidae (scavenger flies) and Muscidae (house flies) were the next most common flower-visiting dipteran families. Dipterans in 12 other families, including the Culicidae or mosquito family, accounted for about $11 \%$ of the visits.

Hymenoptera (bees and wasps) were second in terms of species abundance and floral visits, outperforming the Lepidoptera (butterflies and moths). Of the hymenopteran families, the family Apidae (bumblebees) was the most active (Fig. 4) followed by the Andrenidae (mining bees) and Halictidae (sweat bees). Hymenoptera in five other families accounted for only $3 \%$ of the visits. Insects in the dipteran and hymenopteran orders visited a similar number of plant species: 28 and 27 species respectively (Fig. 5).

\section{Discussion}

Many groups of insects are anthophilous, making use of flowers as resting and hunting sites, or as a source of nectar and pollen. A subset of these flower visitors are pollinators, transferring the pollen from the anthers of one flower to the stigma of another. The efficacy of a pollinator depends on 


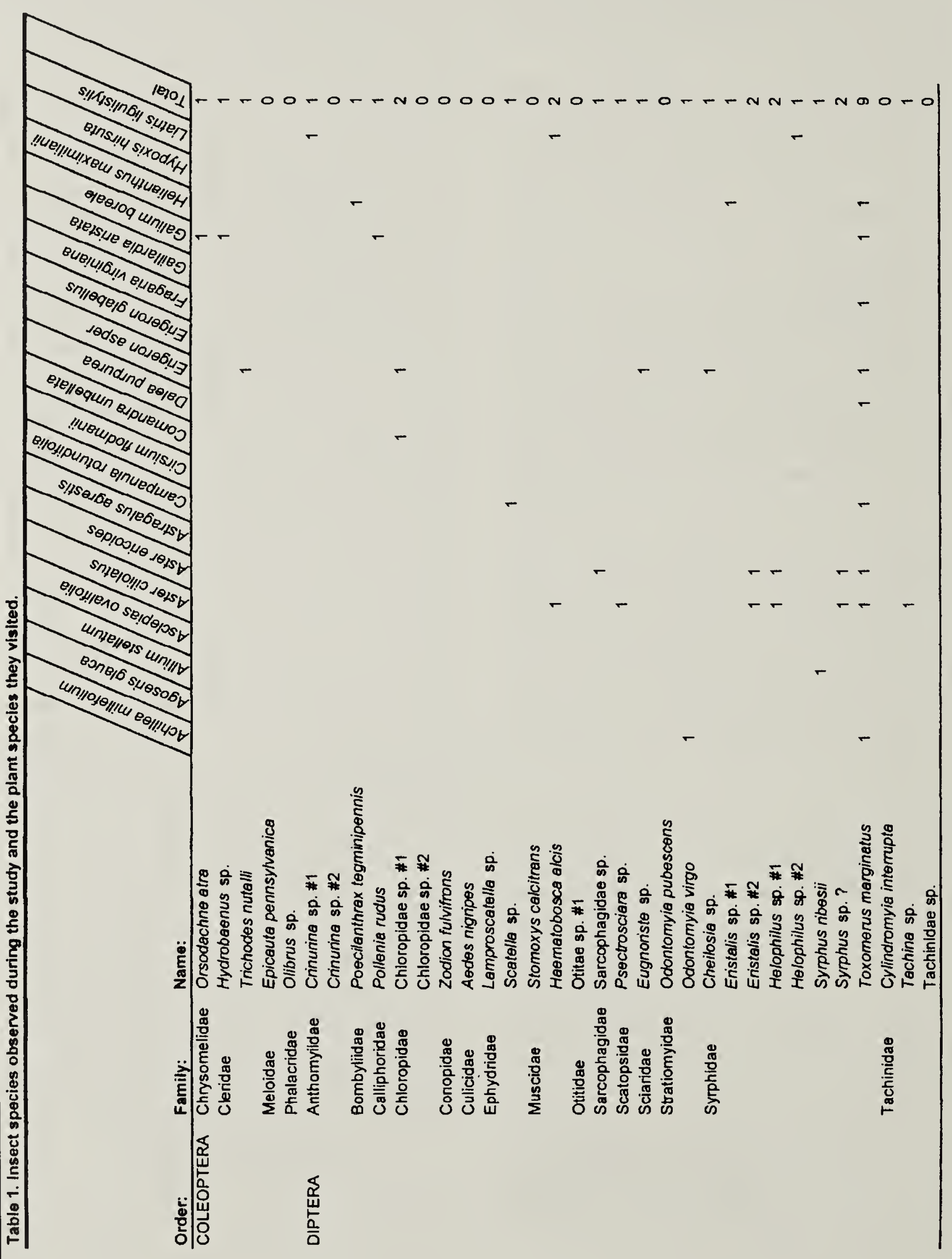




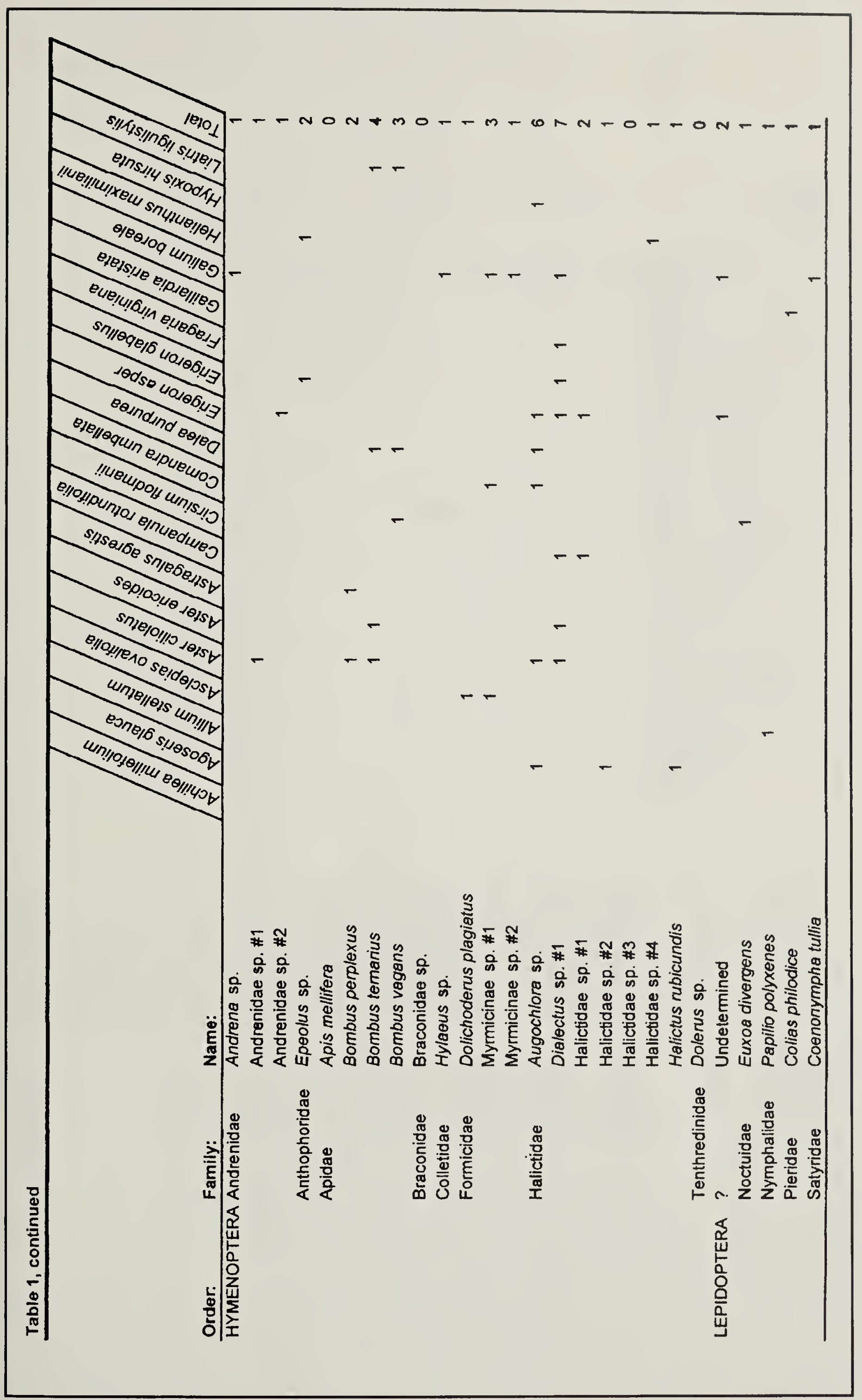

64 (2). June 2006 


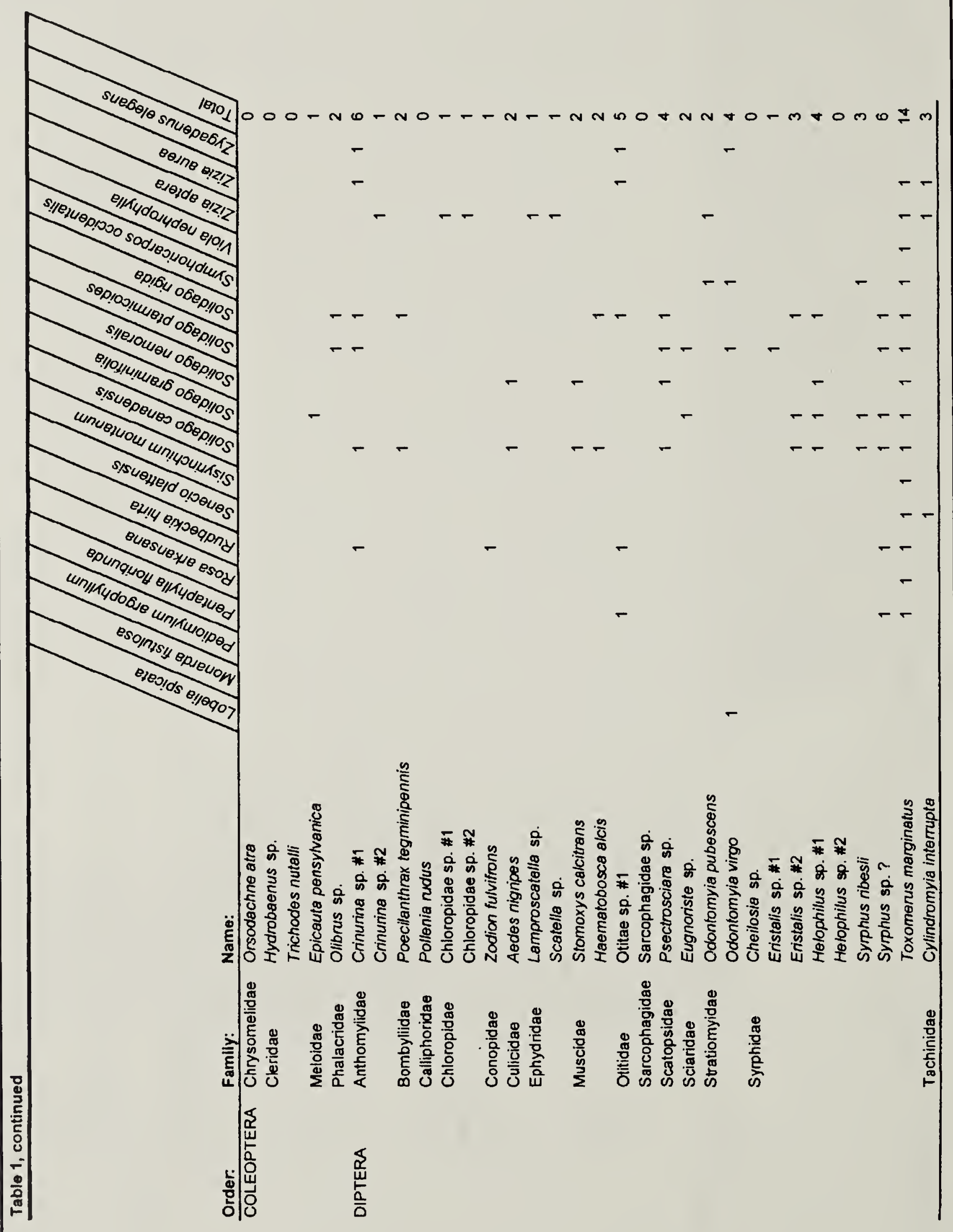




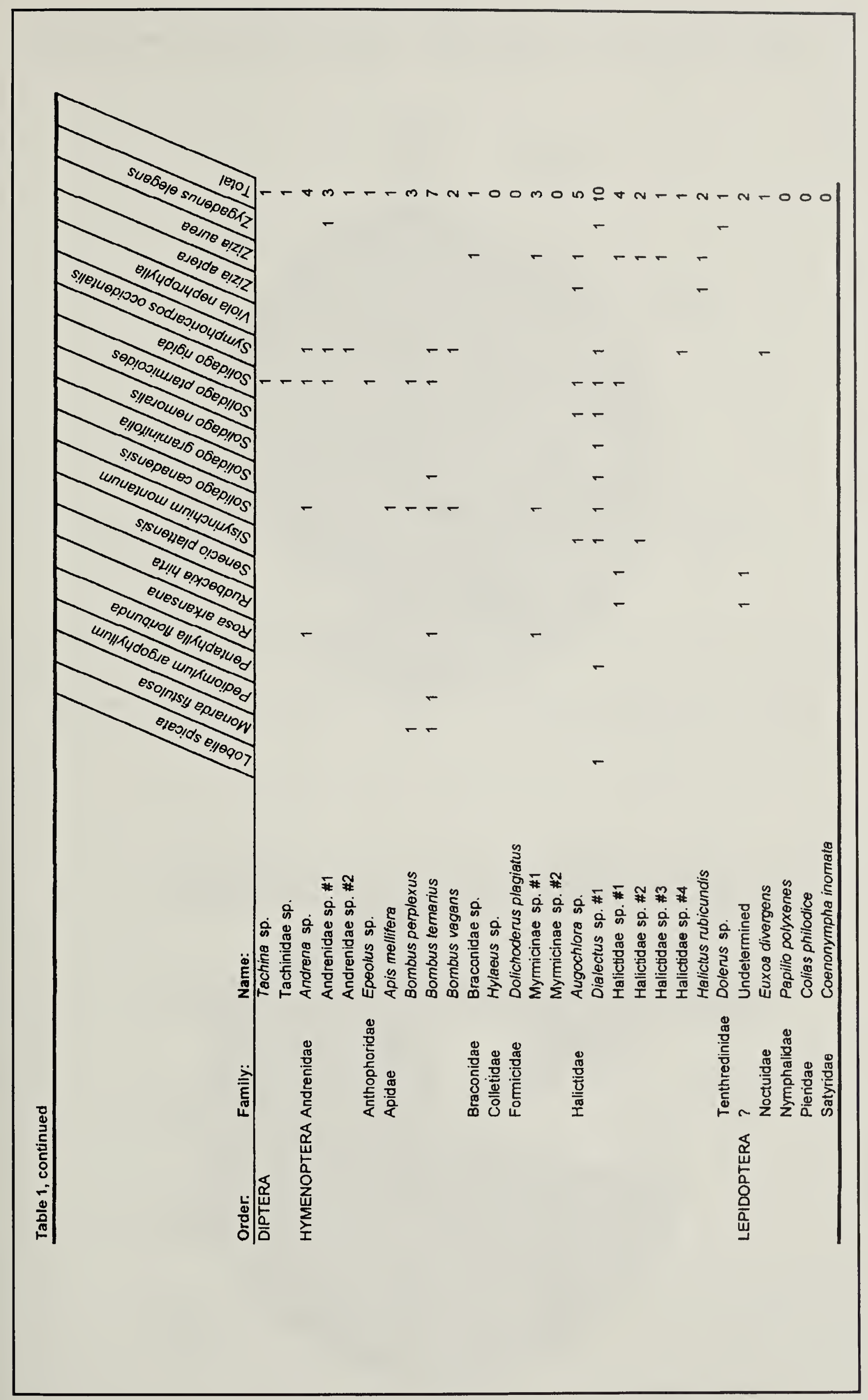


Figure 2. Insect visits observed at two tallgrass prairie preserves in Manitoba $(n=7519)$

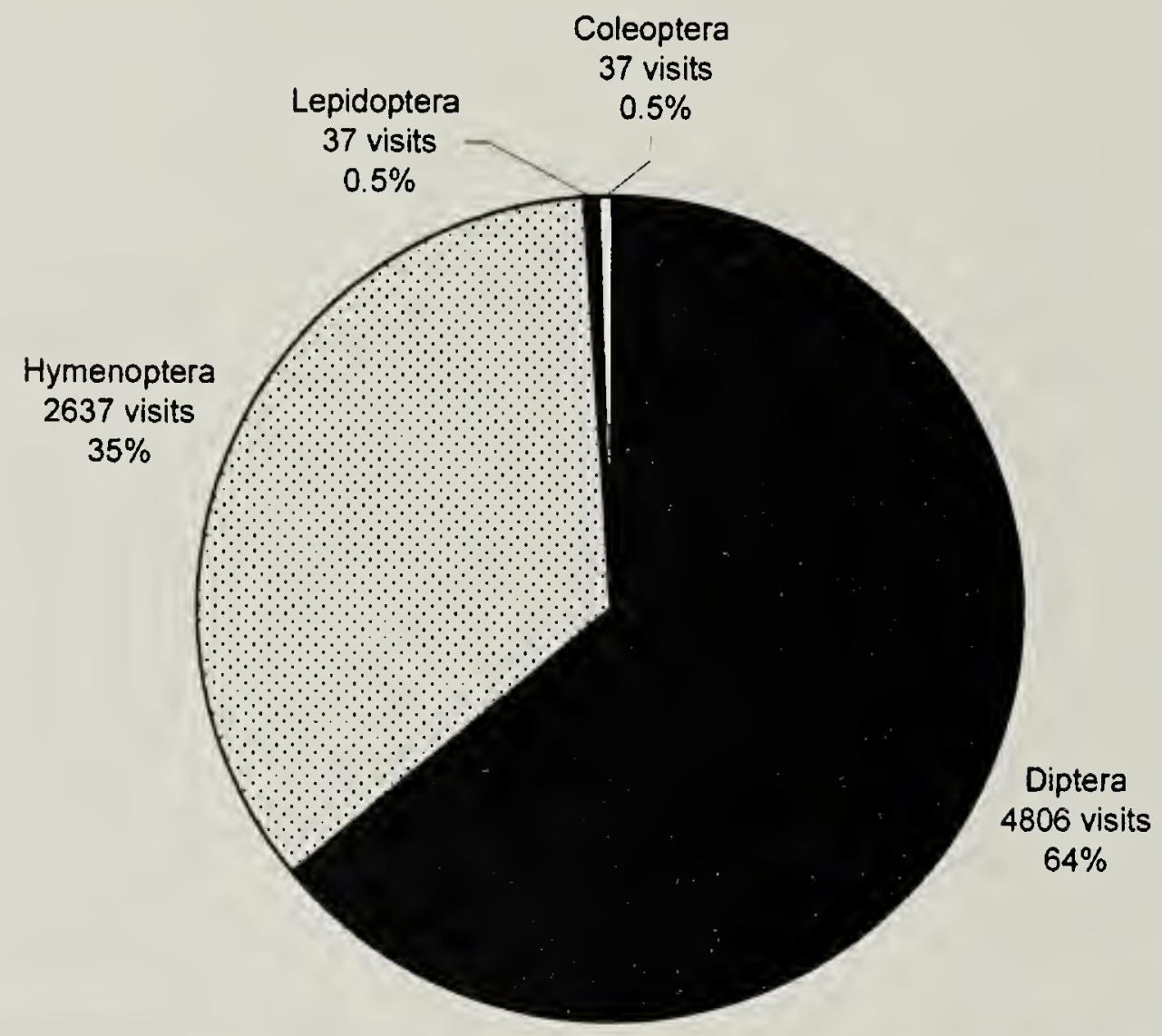

Figure 3. Percentage of visits by families in the order Diptera $(n=4806)$

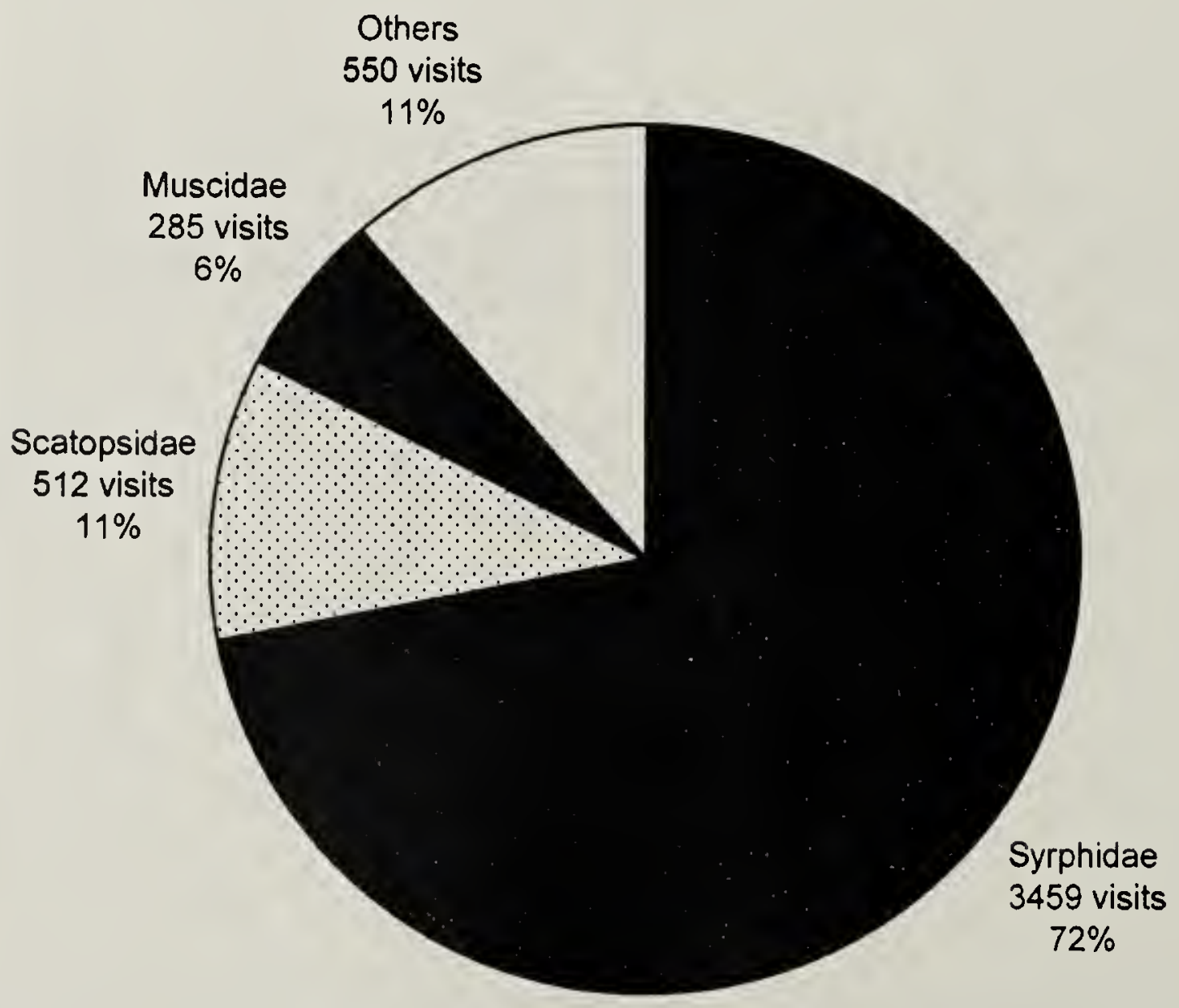


Figure 4. Percentage of visits by families in the order Hymenoptera $(n=2637$ )
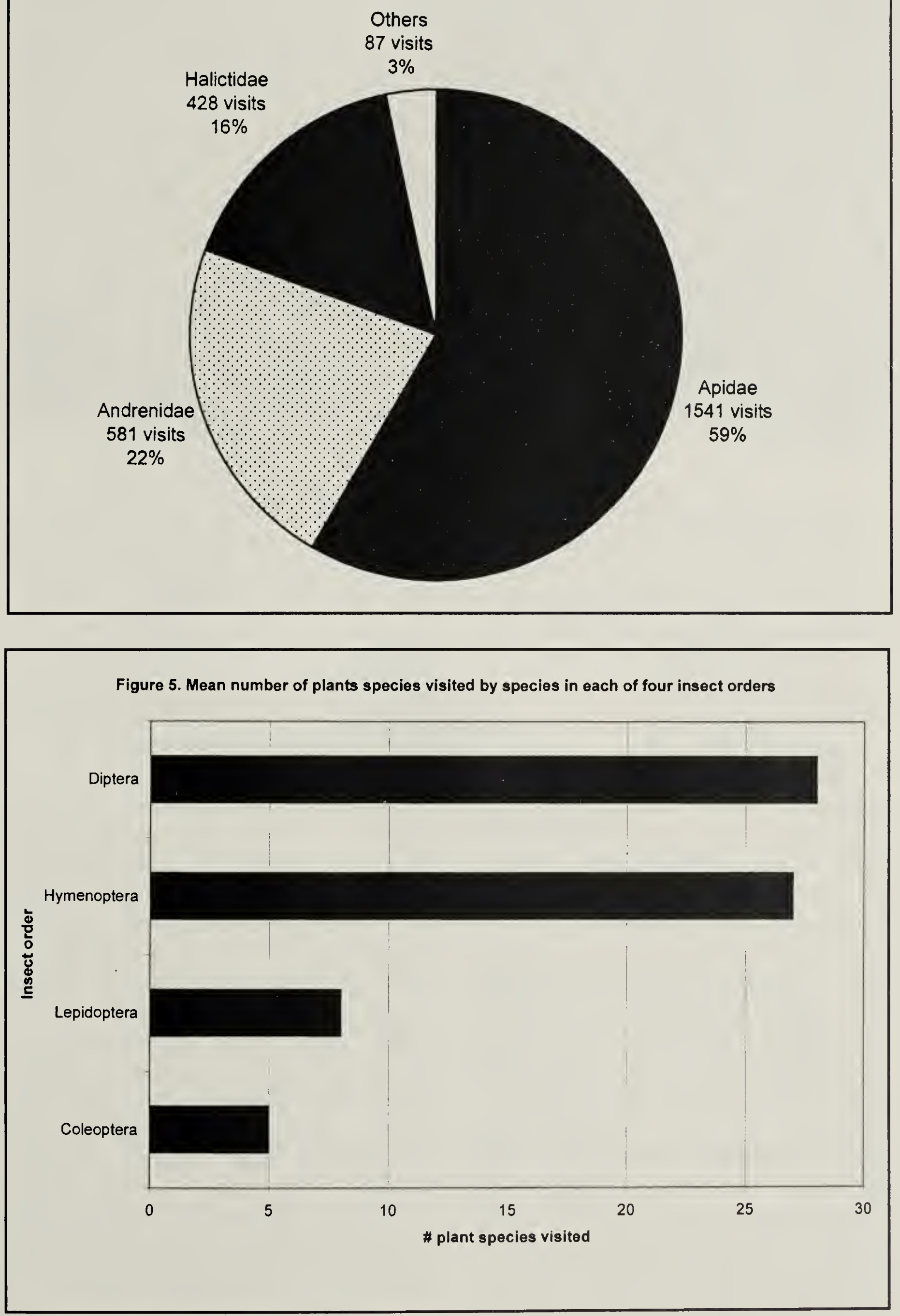

64 (2). June 2006 


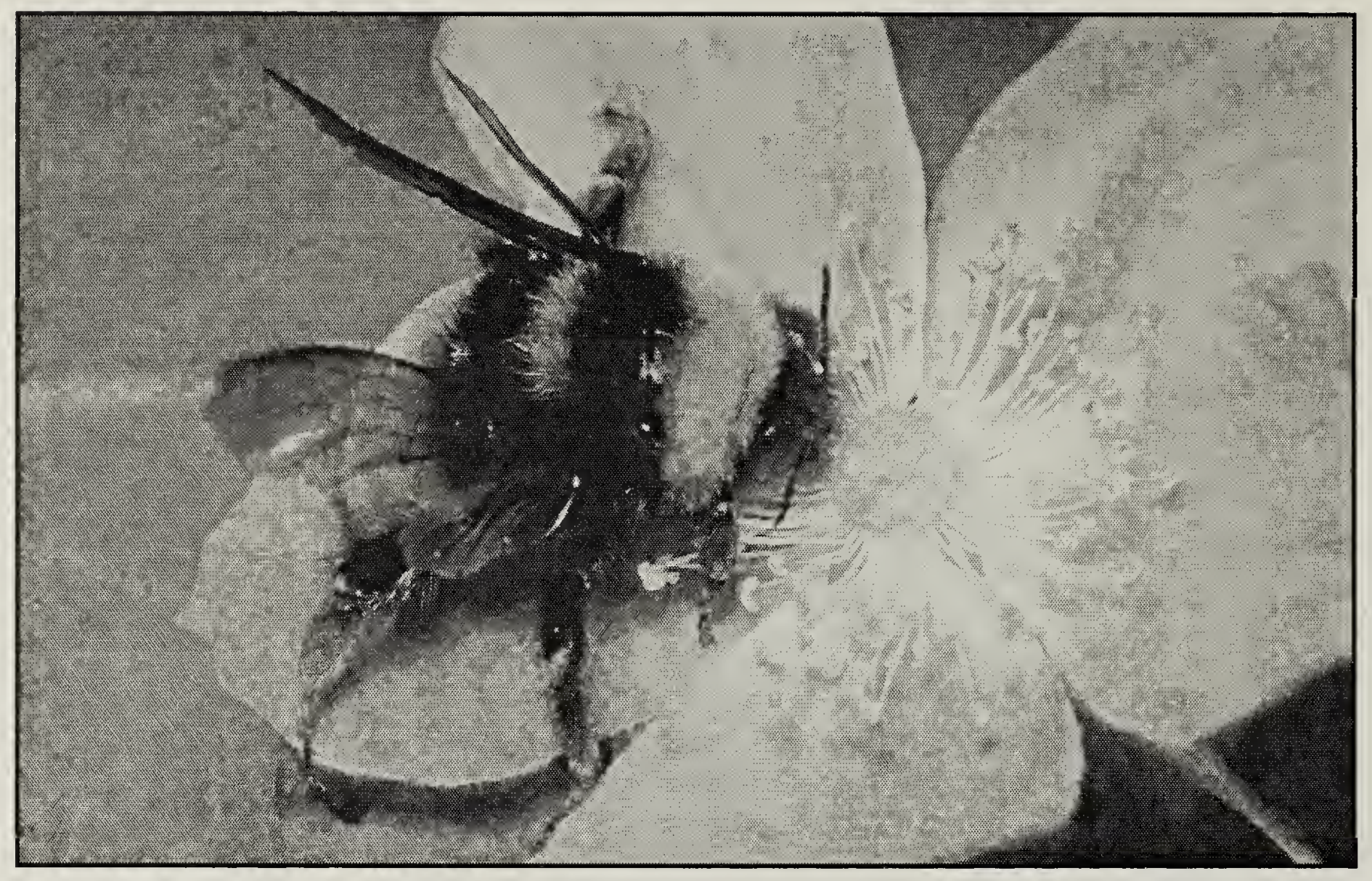

the quality (i.e. proportion of conspecific versus foreign pollen) and quantity of pollen received by a plant from that species. ${ }^{2}$ The observation of an insect feeding on nectar or collecting pollen means that the insect is a potential pollinator of that plant but of unknown efficacy.

These data indicate that dipterans, particularly hover flies, may play an important role in the pollination of plants in the tallgrass prairie. The lack of observations of lepidopterans throughout the entire summer, and the low number of bee visits early in the year, were likely due to the relatively cool, wet weather experienced in Manitoba in 2004. The provincial mean temperature from June to September was $15.3^{\circ} \mathrm{C}$ (the long-term average is $16.8^{\circ} \mathrm{C}$ ) and the total precipitation from May to September nearly $450 \mathrm{~mm}$ (the long term average is $350 \mathrm{~mm}$ ). Butterflies and bees generally require warmer temperatures before they become active (R. Roughley, Curator, J.B. Wallis Museum, University of
Manitoba, pers. comm., 2004). Furthermore, the high moisture levels, particularly at the poorly drained TGPP site, may have reduced the available habitat for ground-dwelling bumblebees. ${ }^{6}$ Thus, the proportion of flower visits among different insects observed in 2004 may not be typical of more average climate conditions.

Despite frequently visiting the same number of flower species, dipterans may be less efficient pollinators than bees, which tend to have higher fidelity to a plant species within a given foraging trip. ${ }^{4}$ Very small flies may be able to "steal" nectar without actually receiving any pollen on their bodies. ${ }^{4}$ Nonetheless many dipteran species have been found to play an important role in plant pollination..$^{3,4}$ The results of this study show that that dipterans are frequent floral visitors in tallgrass prairie and may be important pollinators, particularly when climatic conditions are too cool for more efficient pollinators like bees and butterflies. 
Aay 291

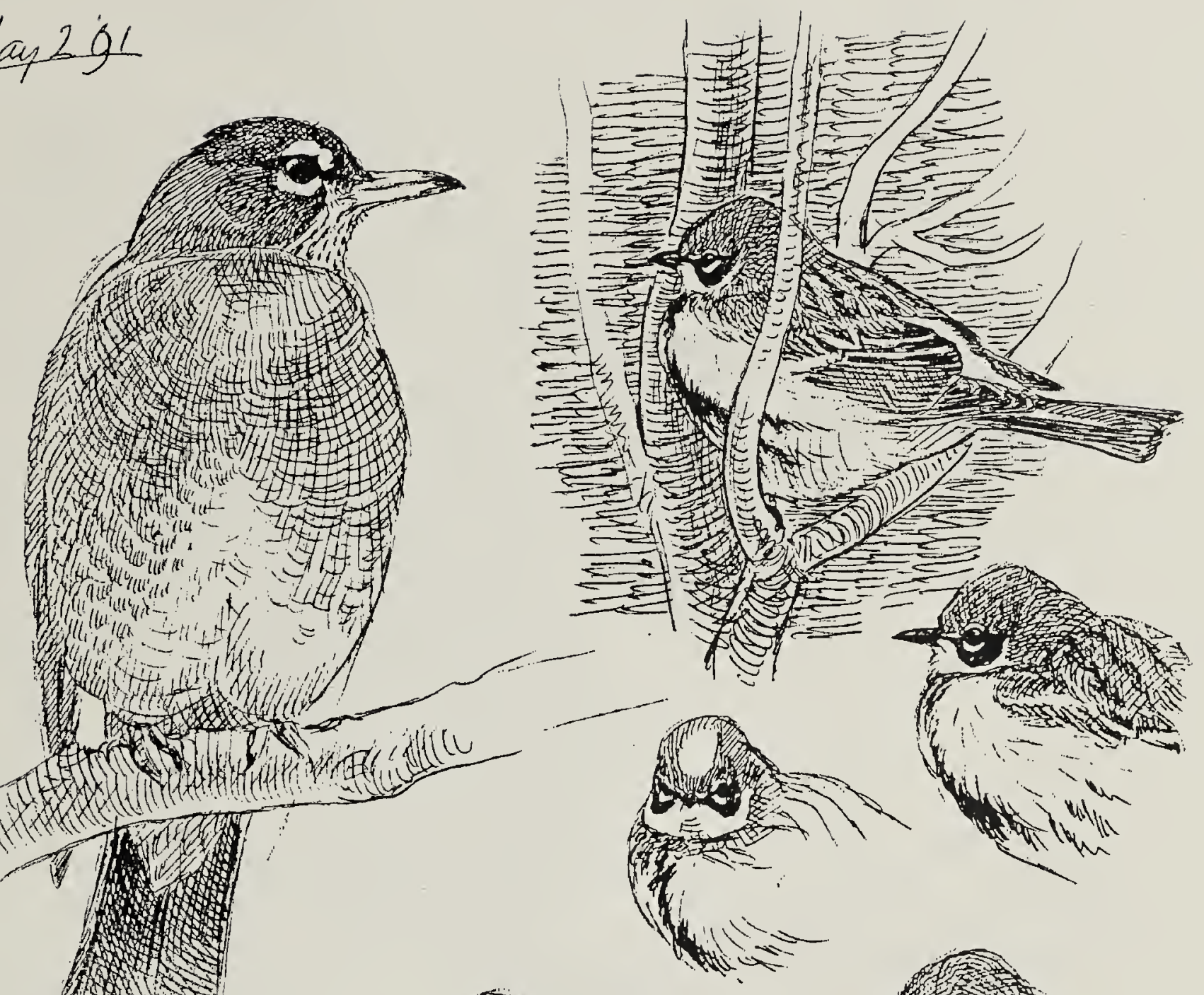

In park, 2 Myrtle whien feeding on berries with Robins.

(c) 安,
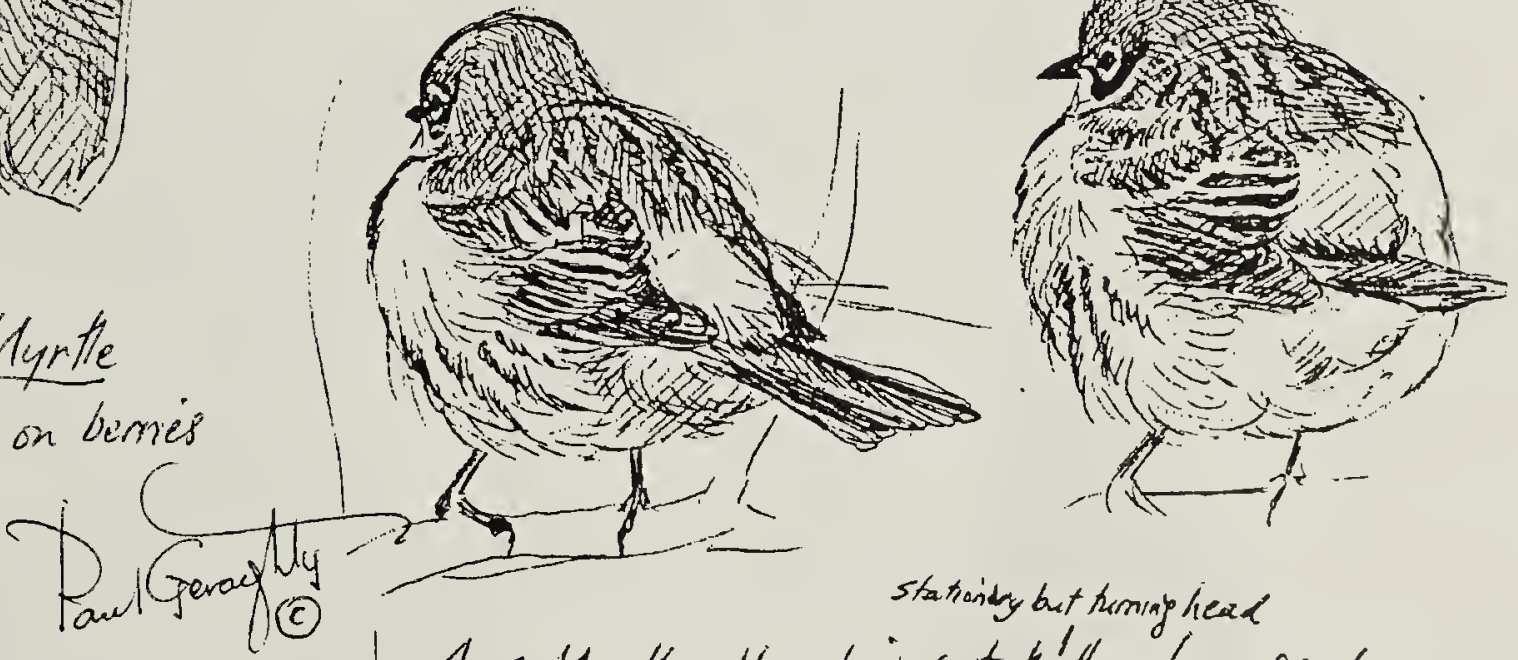

Stationiby but homing lieal

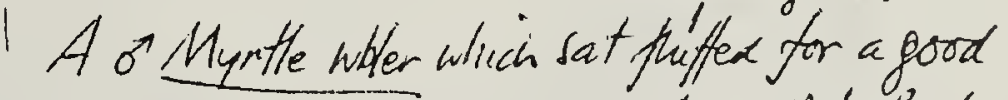
ten nirnutes hr. min pled care Asphalt hites lool. $30^{78}$ and 19 joined it in thee but were all nove acrive. But he frivally fritted a bout \& Diten away $\bar{c}$ others. 


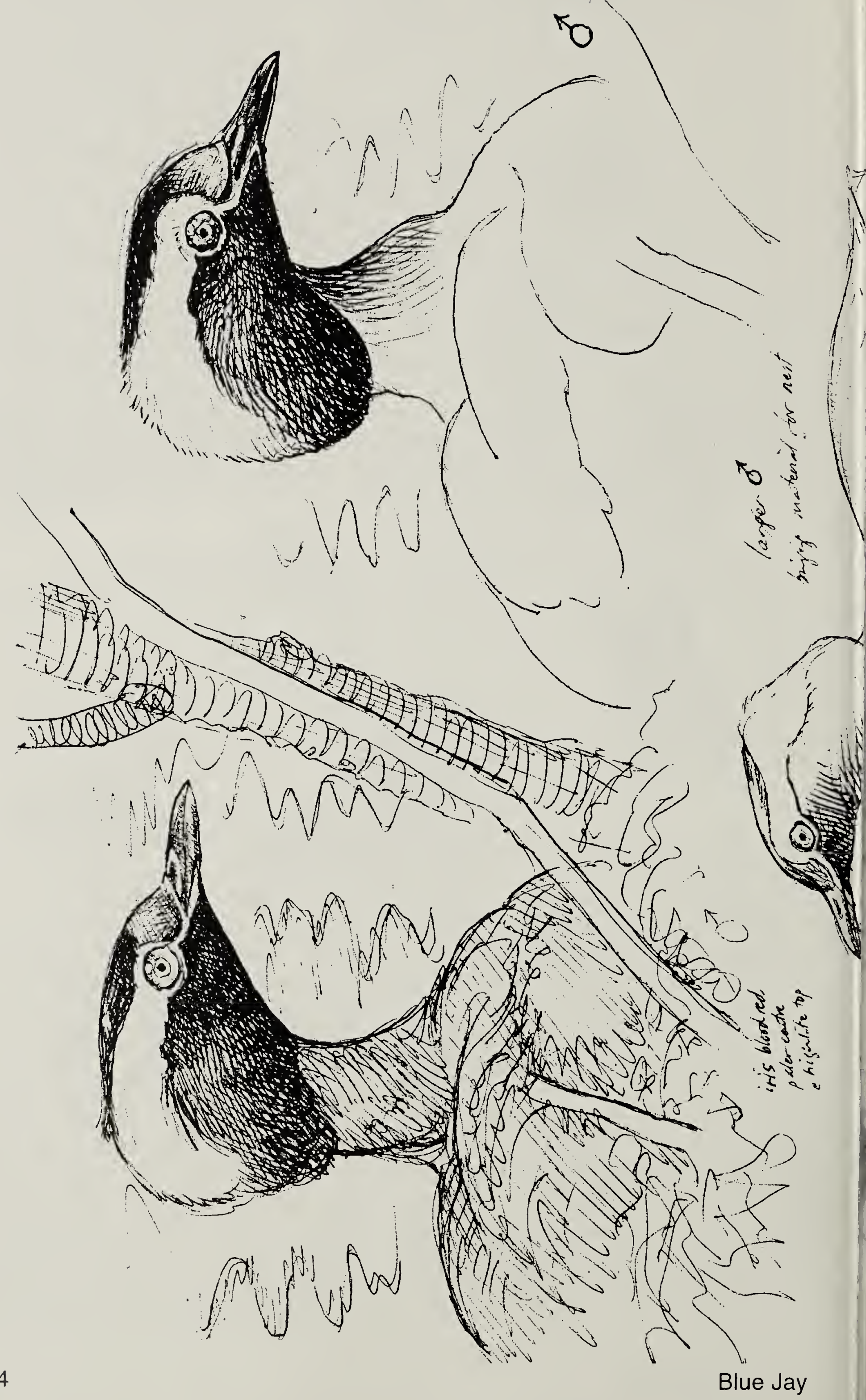




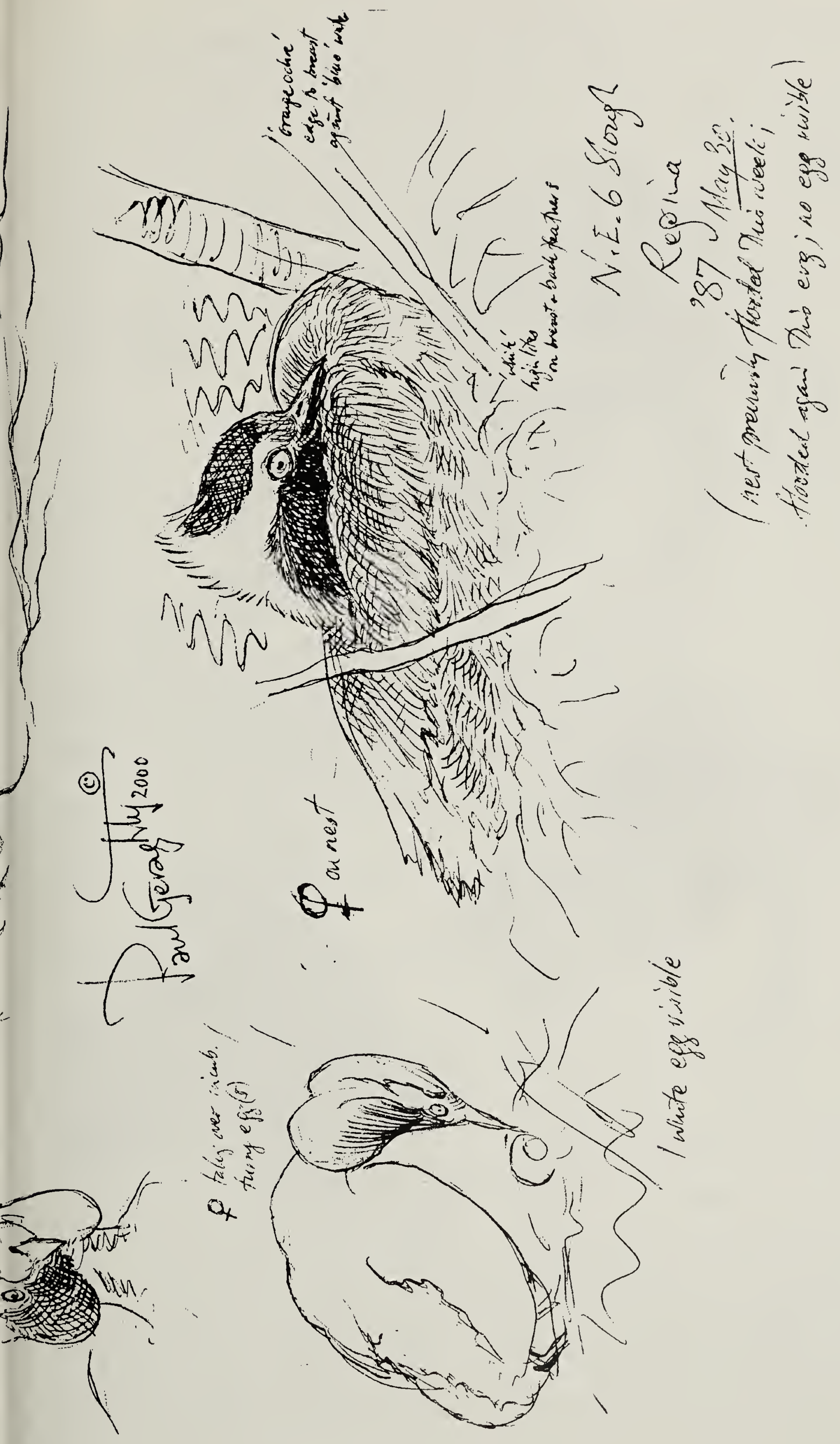




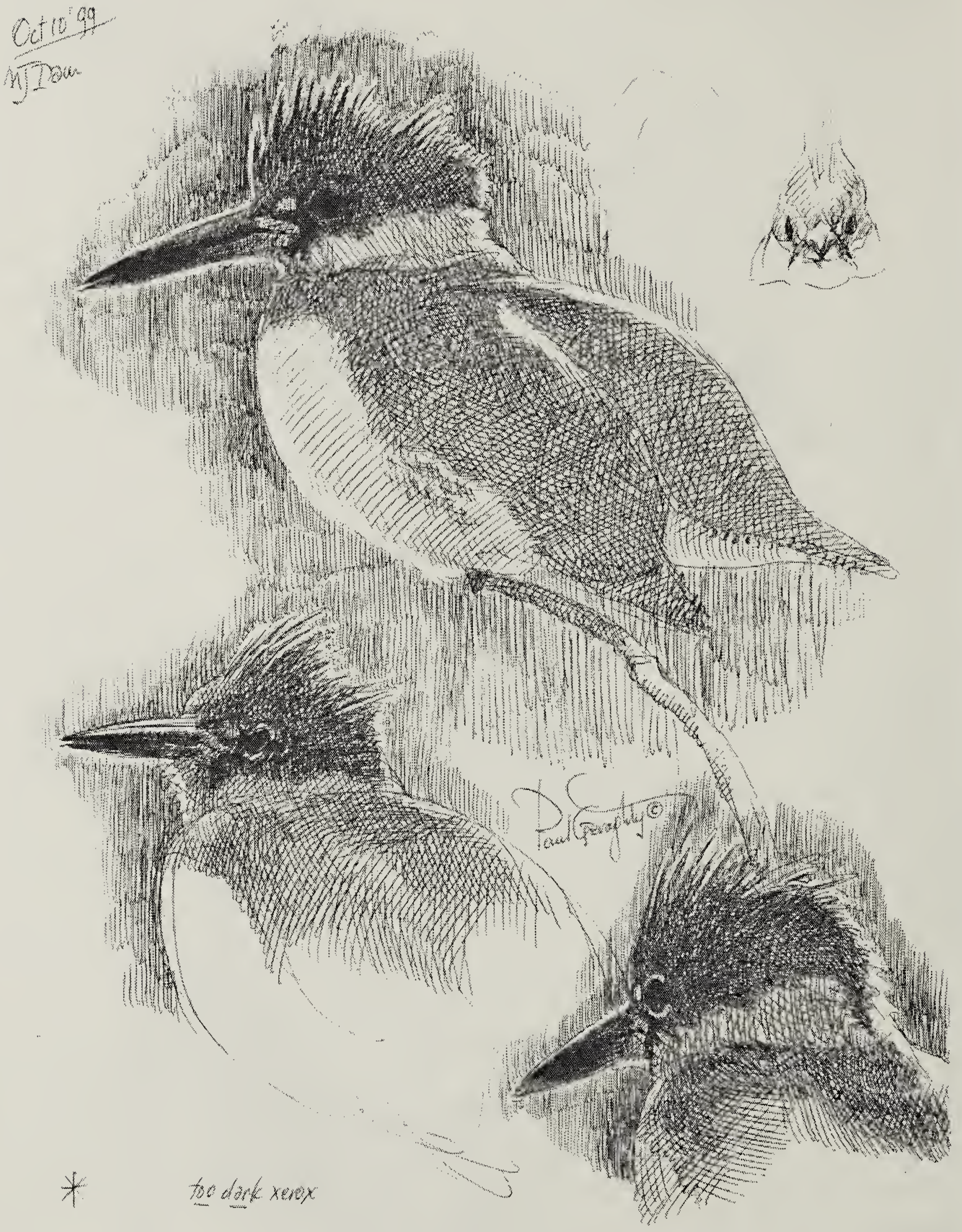




\section{Acknowledgements}

Support for this research was received from the Manitoba Government's Sustainable Development Innovation Fund and The Manitoba Museum Foundation. Volunteers from the Manitoba Museum, namely Karen Sereda, Janice Gallwey and Teresa Forhan, aided in the field work and specimen processing. Special thanks for Heather White for identifying the insect collection.

1. IMES, R. 2000. Beginner's Guide to Entomology. Chancellor Press, London, U.K.

2. KEARNS, C.A., INOUYE, D.W. and WASER, N.M. 1998. Endangered mutualisms: the conservation of plant-pollinator interactions.
Annual Review of Ecology and Systematics 29:83112.

3. KEVAN, P.G. 1972. Insect pollination of high arctic flowers. Journal of Ecology 60:831-848.

4. KEVAN, P.G. and BAKER, H.G. 1983. Insects as flower visitors and pollinators. Annual Review of Entomology 28:407-453.

5. LARSON, B.M.H., KEVAN, P.G. and INOUYE, D.W. 2001. Flies and flowers: taxonomic diversity of anthophiles and pollination. Canadian Entomologist 133:439-466.

6. RICHARDS, K.W. and KEVAN, P.G. 2002. Aspects of bee biodiversity, crop pollination, and conservation in Canada. In Pollinating Bees The Conservation Link Between Agriculture and Nature (P. Kevan and V.L. Imperatriz Fonseca, eds.). Ministry of the Environment, Brasilia.

\section{CHECKLIST OF SASKATCHEWAN MOTHS: PART 15 - LUTE STRINGS, HOOKTIPS, URANIIDS AND GEOMETRIDS (1)}

RONALD R. HOOPER, Box 757, Ft. Qu'Appelle, SK SOG 1S0

Parts 1 to 14 of this Saskatchewan moths series were previously published in Blue Jay and I am planning to write up more families in the near future.

Unless otherwise indicated, all the species are represented in the Royal Saskatchewan Museum collection in Regina. The species are arranged according to the website of Jim Troubridge and Don Lafontaine, Moths of Canada, updated by Greg Pohl in 2006. ${ }^{6}$ This website also has color photographs of the moths. Other helpful websites and references are listed at the end of the article. The common names that are used are mostly according to R. J. L. Jones and C. V. Covell, Jr. ${ }^{1,2}$ Recent name changes are according to Minet and Scoble, and Scoble. ${ }^{4,5}$

In this article, the size and early and late dates of Saskatchewan specimens is given. Some of the recorded food plants are mentioned. Abbreviations: $\mathrm{s}=$ south, $\mathrm{n}=$ north, $\mathrm{w}=$ west, e=east, $\mathrm{CNC}=$ Canadian National Collection in Ottawa. 